\title{
Isolation and Characterization of Flavones from Artemisia monosperma
}

\author{
Lubna Abu-Niaaj*, Ibrahim Katampe
}

\section{Lubna Abu-Niaaj*} Ibrahim Katampe

Department of Natural Sciences, Central State University, 1400 Brush

Row Road, Wilberforce, $\mathrm{OH} 45384$, USA.

\section{Correspondence:}

Lubna F. Abu-Niaaj, Assistant Professor of Biology, Department of Natural Sciences, Central State University, 1400 Brush Row Road, Wilberforce, OH 45384, USA.

Phone: +001-9373766360

E-mail: Labu-niaaj@centralstate.edu

History

- Submission Date: 10-04-2018;

- Review completed:29-05-2018;

- Accepted Date: 16-07-2018

DOI : 10.5530/pj.2018.5.173

Article Available online

http://www.phcogj.com/v10/i5

\section{Copyright}

(c) 2018 Phcog.Net. This is an openaccess article distributed under the terms of the Creative Commons Attribution 4.0 International license.

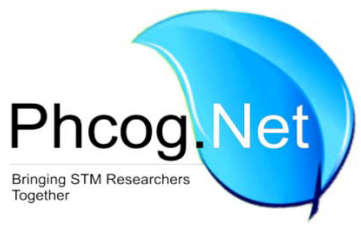

\begin{abstract}
Background: Artemisia monosperma (Delile) is a green aromatic shrub that grows widely in the deserts of Middle East, Africa and China. This plant is commonly used in folk medicine as a remedy of a wide range of illness including gastrointestinal disorders, inflammation, diabetes and microbial infection. The different categories of the secondary metabolites identified from Artemisia species are recognized for their biological activities as antioxidants, anti-inflammatory and antimicrobial compounds. Objective: This study aims to isolate new flavonoids from A. monosperma that might have potential biological activities thus be translated into pharmaceutical uses. Materials and Methods: Air-dried A. monosperma extraction was done using different organic solvents. The methanolic extract was selected for isolation of flavonoids using column chromatography and thin layer chromatography. The chemical structures of the isolated flavones determined based on spectroscopic analysis of ultraviolet, mass and nuclear magnetic resonance spectra. Results: Nine flavone aglycones were isolated and identified from the methanolic extract; four of which are reported for the first time from A. monosperma. These include: 5-Hydroxy-3',4', 6,7-tetramethoxyflavone; 3',5-dihydroxy-4',6,7-trimethoxyflavone (eupatorin); 5,6-dihydroxy-4',7-dimethoxyflavone(ladanein); and 2',4',5-trihydroxy-5',6,7trimethoxyflavone (arcapillin). The remaining five flavones were previously identified from this plant as : 4',5-Dihydroxy-3',6,7-tri-methoxyflavone(cirsilineol);5,7-dihydroxy-3', 4', 6-trimethoxyflavone (eupatilin);4',5,7-trihydroxy-3',6-dimethoxyflavone(jaceosidin);4',5-dihydroxy-6,7-dimethoxy-flavone (circimaritin) and 4',5,7-trihydroxy-6-methoxyflavone (hispidulin). In addition, two acetophenone derivatives were isolated from fractions yielded selected flavones and these were identified as 4-hydroxyacetophenone and 3-(2-hydroxymethyl-2-buten-4-yl)-4-hydroxyaceto-phenone. Conclusion: This successful isolation of these natural flavonoids from $A$. monosperma can contribute further to the evaluation of bioactive compounds against disorders including but not limited to inflammatory associated disorders and microbial infections.
\end{abstract}

Key words: Artemisia monosperma, Flavones, Antioxidants, Antimicrobial activity,

\section{INTRODUCTION}

Artemisia monosperma (Delile) is a green aromatic perennial shrub that belongs to the family Asteraceae (Compositae) and it grows widely in the deserts of Middle East, Africa and China. ${ }^{1-3}$ The plant is reputed in folk medicine for treatment of gastrointestinal disorders, ${ }^{4}$ diabetes, ${ }^{5}$ rheumatic pain, fever and to induce abortion. ${ }^{6}$ In addition to the high antioxidant activity, ${ }^{7}$ A. monosperma is reported for antimicrobial activities $^{8-9}$ as well as its insecticidal and antimalarial potentiation. ${ }^{10-13}$ Grech-Baran and Pietrosiuk ${ }^{14}$ reported the synthesis of two drugs, Artemisinin and Arglabin, first isolated from Artemisia species. ${ }^{15}$ Artemisinin derivatives have become standard treatment worldwide against malaria while Arglabin and its derivatives have shown antitumor activity against multiple tumor cell lines. ${ }^{16}$ The wide-range of biological activities of A. monosperma is due to its content of a vari- ety of secondary metabolites such as flavonoids, ${ }^{17-20}$ alkaloids, ${ }^{9}$ coumarins, ${ }^{21-22}$ acetylenic compounds, ${ }^{2,13}$ oils, ${ }^{1,23-32}$ and terpenoids. ${ }^{33}$ This study aims to isolate new flavonoids from Artemisia monosperma of potential pharmaceutical activities.

\section{MATERIALS AND METHODS}

\section{Collection of Plant}

Artemisia monosperma (Delile) was collected from the Southern desert of Jordan near Irwaishid. The voucher specimen was authenticated by professor Dawud El-Eisawi, a botanist of the University of Jordan and it was deposited as "S. Abdalla \#251", in the herbarium of University of Jordan, Amman, Jordan. The collected plant was air dried away from the direct sunlight.
Cite this article: Abu-Niaaj L, Katampe I. Isolation and Characterization of Flavones from Artemisia monosperma, Pharmacogn J. 2018;10(5):1018-23. 


\section{Extraction of Plant}

Several organic solvents were used to extract flavonoids from the plant. The dried plant $(7.0 \mathrm{Kg})$ was immersed in petroleum ether at room temperature for 10 days with frequent agitation to extract lipids. The petroleum ether was filtered, evaporated under reduced pressure to give a crude extract that was kept for later use. The plant material was further extracted repeatedly with multiple organic solvent systems as shown in Figure 1. All chemicals and organic solvents used were of analytical grade and purchased from Fisher Scientific.

\section{Fractionation of the Methanolic Crude Extract}

The methanolic crude extract (183 g) was subjected to fractionation using column chromatography and Thin Layer Chromatography (TLC). It was adsorbed on $150 \mathrm{~g}$ silica gel, and loaded on a previously packed silica gel column with chloroform $(8 \mathrm{~cm} \times 60 \mathrm{~cm}, 1 \mathrm{~kg}$ silica gel 60 PF254, 70-230 mesh). Elution of the column was initially with chloroform then the polarity was increased gradually by adding $95 \%$ ethanol and /or methanol. Eluents collected in $500 \mathrm{ml}$, analyzed by TLC, and combined into twelve fractions that were concentrated and subjected to further fractionation by column chromatography.

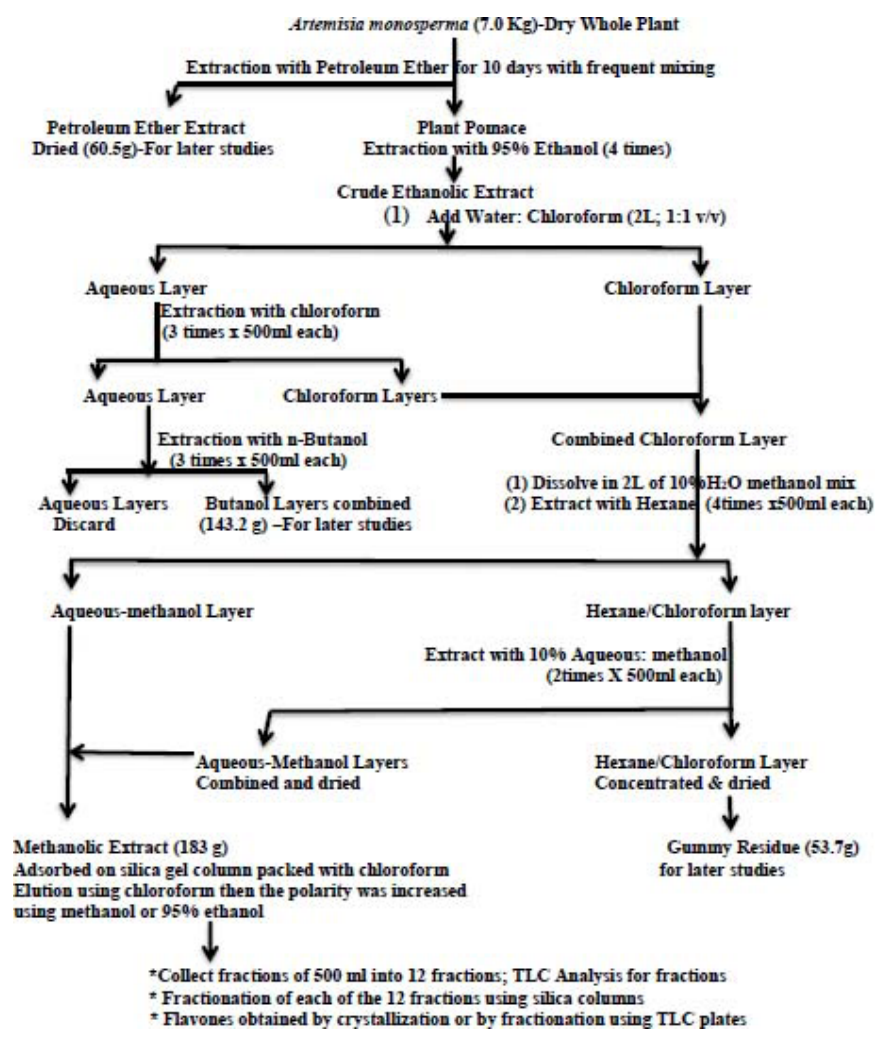

Figure 1: Isolation of Different Flavones from Artemisia monosperma (Delile)

\section{Purification}

The identified flavones were isolated from eight fractions subjected to column chromatography. Each selected fraction was loaded on a silica column (0.35-0.50 Kg silica gel 60 PF254) packed in benzene: ethyl acetate $(85 \%-75 \%)$. The loaded quantities were: fraction II (10.7g); fraction III (8.0g of 14.2g); fraction IV (11.7 g); fraction V (15g of $25 \mathrm{~g}$ ), frac- tion VI (8.0g); fraction VII (7.5g); VIII (7.5g). The polarity of the eluted solvent was increased gradually until pure ethyl acetate was reached. Fractions were collected in $500 \mathrm{ml}$ and combined according to their TLC analysis. Further purification of fractions was achieved by either crystallization or by fractionation by TLC plates using suitable solvent systems. The structural elucidation of compounds was achieved by spectral analysis of ${ }^{1} \mathrm{H}-\mathrm{NMR}, \mathrm{UV}$, and mass data.

\section{Ultraviolet (UV) Analysis}

UV spectra were recorded on a Nikon 810 spectrophotometer. Identification of functional groups on the flavone nucleus was obtained by comparison of the spectrum of the compound in methanol to those obtained in the presence of acidic or basic shift reagents (sodium methoxide, aluminum chloride in presence or absence of hydrochloric acid).

\section{Mass Spectroscopy Analysis}

The mass spectral data obtained by the electron impact method (eim) at 70-90 eV on a kratos MS 9/50 double-focusing high resolution mass spectrophotometer.

\section{Nuclear Magnetic Resonance (NMR) Spectroscopic Analysis}

The proton nuclear magnetic resonance (200 MHz $\left.{ }^{1} \mathrm{H}-\mathrm{NMR}\right)$ spectra were recorded on a Brucker WP-200 spectrometer. Proton chemical shifts presented as parts per million (ppm) on a scale relative to tetramethylsilane using a deuterated chloroform peak at $7.26 \mathrm{ppm}$ as an internal standard. Low-soluble compounds were dissolved in hexadeuteriodimethyl sulfoxide (DMSO- $\mathrm{d}_{6}$ ). The coupling constants are given in Hertz (Hz).

\section{RESULTS}

Four flavone aglycones are reported for the first time from A. monosperma. These are: 5-hydroxy-6,7, 3?,4?-tetramethoxyflavone, ladanein, eupatorin and arcapillin. Other five previously reported flavone aglycones are identified as: eupatilin, circimaritin, cirsilineol, hispidulin, and jaceosidin. Table 1 lists the obtained flavones, their chemical formula, common names, quantities, and molecular weights. The structural elucidation of compounds was achieved by spectral analysis of proton nuclear magnetic resonance, ultraviolet, and mass data. Table 2 lists the analysis of UV spectra, and Figure 2 shows the ${ }^{1} \mathrm{H}-\mathrm{NMR}$ spectra. The organic solvent mixtures used to obtain the flavones by crystallization or by fractionation using TLC plates as listed in Table 3.

Two acetophenone derivatives were also isolated and identified as 4-hydroxyacetophenone (Figure 3) and 3-(2- Hydroxymethyl-2-buten4-yl)-4-Hydroxyacetophenone (Figure 4) from fractions previously yielded flavones. The TLC of fraction IV using chloroform: methanol: ammonia gas $(8: 2 \mathrm{v} / \mathrm{v})$ produced $115 \mathrm{mg}$ of 4-Hydroxyacetophenone which is known as piceol. $500 \mathrm{mg}$ of 3-(2- Hydroxymethyl-2-buten4-yl)-4- hydroxyacetophenone was obtained by TLC of fractions V and VII using chloroform: methanol: ammonia gas (7.5: $2.5 \mathrm{v} / \mathrm{v})$. The UV spectrum of this compound in methanol showed a band at 278 which was shifted to 354 upon addition of sodium methoxide indicating the presence of a phenolic group. The mass spectrum showed a molecular ion peak at $\mathrm{m} / \mathrm{e} 202$ due to the loss of a water molecule.

\section{DISCUSSION}

Flavones, a subgroup of flavonoids, have a basic skeleton that consists of three rings as shown below. The antioxidant activity of flavonoids is 
Table 1: Flavones isolated from Artemisia monosperma (Delile); chemical names and structures, common names, obtained quantities and molecular formula

\begin{tabular}{|c|c|c|c|c|c|}
\hline & Chemical Name of Compounds & Chemical Structure & Common Name & Quantity (mg) & $\operatorname{Mr}(\mathrm{g} / \mathrm{mol})$ \\
\hline 1 & 5-Hydroxy-3',4',6,7-tetramethoxyflavone & & ${ }^{*} \mathrm{~N} / \mathrm{A}$ & 175 & 358 \\
\hline 2 & 3',5-Dihydroxy-4',6,7-trimethoxyflavone & & ${ }^{\star}$ Eupatorin & 70 & 344 \\
\hline 3 & 5,6-Dihydroxy-4',7-dimethoxyflavone & & ${ }^{*}$ Ladanein & 55 & 314 \\
\hline 4 & 5,7-Dihydroxy-3',4',6-trimethoxyflavone & & Eupatilin & 640 & 344 \\
\hline 5 & 4',5-Dihydroxy-3',6,7-trimethoxyflavone & & Cirsilineol & 280 & 344 \\
\hline 6 & 4',5,7-Trihydroxy-3',6-dimethoxyflavone & & Jaceosidin & 60 & 330 \\
\hline 7 & 4',5-Dihydroxy-6,7-dimethoxyflavone & & Cirsimaritin & 415 & 314 \\
\hline 8 & 4',5,7-Trihydroxy-6-methoxyflavone & & Hispidulin & 20 & 300 \\
\hline 9 & 2',4',5-Trihydroxy-5',6,7-trimethoxyflavone & & ${ }^{\star A}$ Arcapillin & 180 & 360 \\
\hline
\end{tabular}

* Indicates flavones isolated for the first time from A. monosperma.

Table 2: UV spectra for the Isolated Flavones from Artemisia monosperma.

\begin{tabular}{|c|c|c|c|c|c|c|}
\hline & Chemical Name of Compounds & $\begin{array}{l}\text { Common } \\
\text { Name }\end{array}$ & $\mathrm{CH}_{3} \mathrm{OH}$ & $\mathrm{NaOCH}_{3}$ & $\mathrm{AlCl}_{3}$ & $\mathrm{ALCl}_{3}+\mathrm{HCl}$ \\
\hline 1 & 5-Hydroxy-3',4', 6,7-tetramethoxyflavone & N/A & 340,278 & 340,288 & 370,286 & 360,289 \\
\hline 2 & 3',5-Dihydroxy-4', 6,7-trimethoxyflavone & Eupatorin & 338,276 & $368,310,276$ & 368,284 & 354,290 \\
\hline 3 & 5,6-Dihydroxy-4',7-dimethoxyflavone & Ladanein & 330,274 & $368,296 s h, 274$ & $354,303 \mathrm{sh}, 280 \mathrm{sh}$ & 350,300 \\
\hline 4 & 5,7-Dihydroxy-3',4',6-trimethoxyflavone & Eupatilin & 342,276 & $370,310,276$ & $370,282,260$ & $358,290,254$ \\
\hline 5 & 4',5-Dihydroxy-3',6,7-trimethoxyflavone & Cirsilineol & $342,276,242$ & 406,304sh, 266 & 376,286 & 364,286 \\
\hline 6 & 4',5,7-Trihydroxy-3',6-dimethoxyflavone & Jaceosidin & 344,274 & $408,338,258 \mathrm{sh}$ & 378,281 sh, 261 & 364,286 \\
\hline 7 & 4',5-Dihydroxy-6,7-dimethoxyflavone & Cirsimaritin & 332,278 & 389,296 sh, 272 & $362,302,290$ sh & $254,300,262 \mathrm{sh}$ \\
\hline 8 & 4',5,7, -Trihydroxy-6-methoxyflavone & Hispidulin & 334,276 & 394,326 & 362,302 & 352,300 \\
\hline 9 & 2',4',5-Trihydroxy-5', 6,7-rimethoxyflavone & Arcapillin & $268,288 \mathrm{sh}$ & $422,322 \mathrm{sh}, 288 \mathrm{sh}$ & $406,316,276$ & 398,316 sh, 278 \\
\hline
\end{tabular}

related to their structure especially the hydroxy substitution of the aromatic $\mathrm{A}$ and $\mathrm{B}$ rings and the substitution pattern of the C-ring. ${ }^{34}$

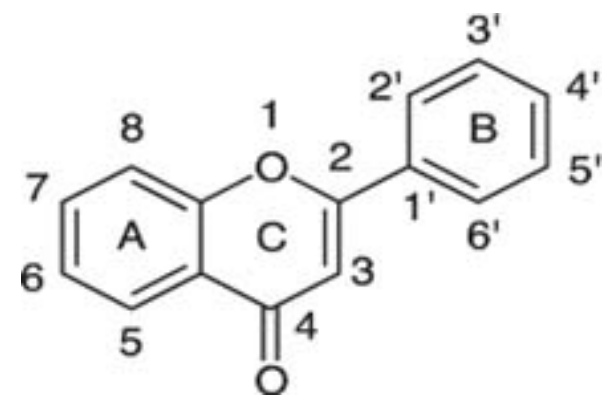

We report the isolation and characterization of nine flavones from the methanolic extract of $A$. monosperma; four of which are reported for the first time from this plant. The five previously reported flavones from Artemisia monosperma are eupatilin, ${ }^{17}$ circimaritin, cirsilineol, jaceosidin and hispidulin. ${ }^{20}$ The data of ${ }^{1} \mathrm{H}-\mathrm{NMR}$, UV and mass obtained for the different flavones match those reported in the literature. ${ }^{20,34-41}$ The two acetophenone derivatives are of importance because of the potential of their anti -oxidative and anti-inflammatory effects of acetophenones. ${ }^{38}$
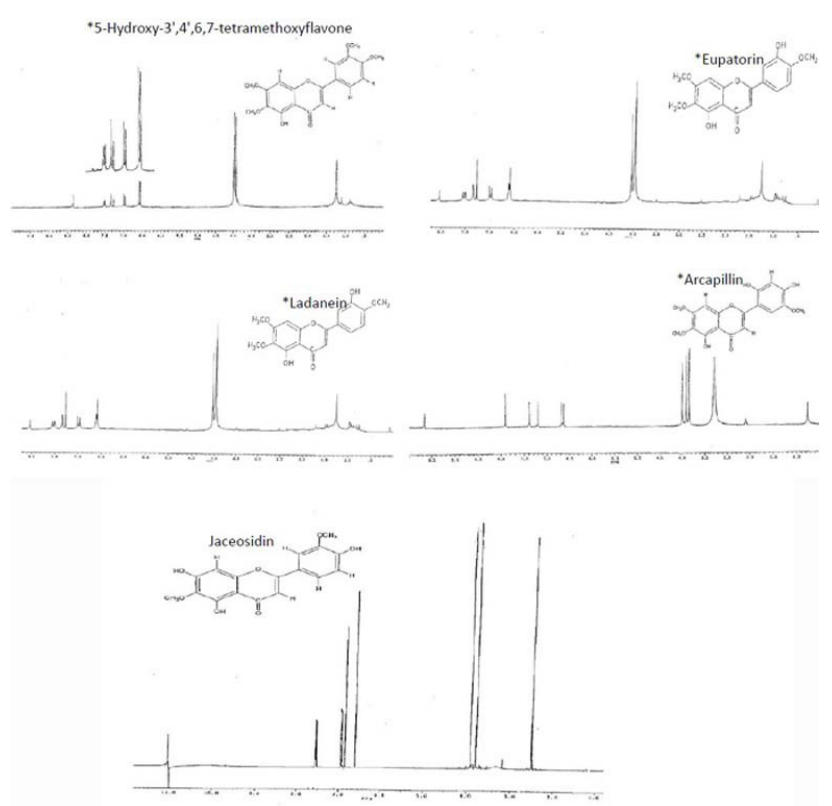

Figure 2: The $200 \mathrm{MHz}{ }^{1} \mathrm{H}-\mathrm{NMR}$ spectra of isolated flavones from A. monosperma. 
Table 3: Purification of flavones using different organic solvent systems.

\begin{tabular}{|c|c|c|c|c|}
\hline & Chemical Name of Compounds & Common Name & Fraction & Solvent Used (v/v) \\
\hline 1 & 5-Hydroxy-3',4',6,7-tetramethoxyflavone & N/A & II & Crystallization from Methanol \\
\hline 2 & 3',5-Dihydroxy-4',6,7-trimethoxyflavone & Eupatorin & II & EtAc: Pet. $(3: 7)$ \\
\hline 3 & 5,6-Dihydroxy-4',7-dimethoxyflavone & Ladanein & II & Ben: $\mathrm{CHCl}_{3}: \mathrm{MeOH}(3: 6: 1)$ \& EtAc: Ben (2:8) \\
\hline 4 & 5,7-Dihydroxy-3',4',6-trimethoxyflavone & Eupatilin & II\&III & Ben: $\mathrm{CHCl}_{3}: \mathrm{MeOH}(3: 6: 1)$ \\
\hline 5 & 4',5-Dihydroxy-3',6,7-trimethoxyflavone & Cirsilineol & II\&III & EtAc: Ben. (3:7)/twice \\
\hline 6 & 4',5,7-Trihydroxy-3',6-dimethoxyflavone & Jaceosidin & IV & Methanol and/or cyclohex: Ac.(7:3) \\
\hline 7 & 4',5-Dihydroxy-6,7-dimethoxyflavone & Cirsimaritin & $\mathrm{V}$ & Methanol or $\mathrm{CHCl}_{3}: \mathrm{MeOH}: \mathrm{NH}_{3}(\mathrm{~g})(8: 2)$ \\
\hline 8 & 4',5,7,-Trihydroxy-6-methoxyflavone & Hispidulin & VI & $\mathrm{CHCl}_{3}: \mathrm{MeOH}: \mathrm{NH}_{3}(\mathrm{~g})(8: 2)$ \\
\hline 9 & 2',4',5-Trihydroxy-5',6,7- trimethoxyflavone & Arcapillin & VI,VII, VIII & $\mathrm{CHCl}_{3}: \mathrm{MeOH}: \mathrm{NH}_{3}(\mathrm{~g})(7.5: 2.5)$ \\
\hline
\end{tabular}

Ben.=Benzene; $\mathrm{CHCl}_{3}=$ Chloroform; $\mathrm{MeOH}=$ Methanol; EtAc. $=$ Ethyl acetate; Pet=Petroleum Ether; $\mathrm{NH}_{3}(\mathrm{~g})=\mathrm{Ammonia}$ Vapor.

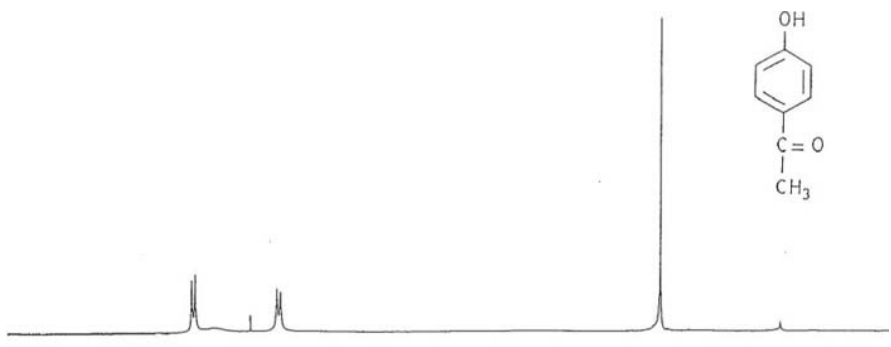

Figure 3: The ${ }^{1} \mathrm{H}-\mathrm{NMR}$ spectrum of 4-Hydroxyacetophenone isolated from A. monosperma.

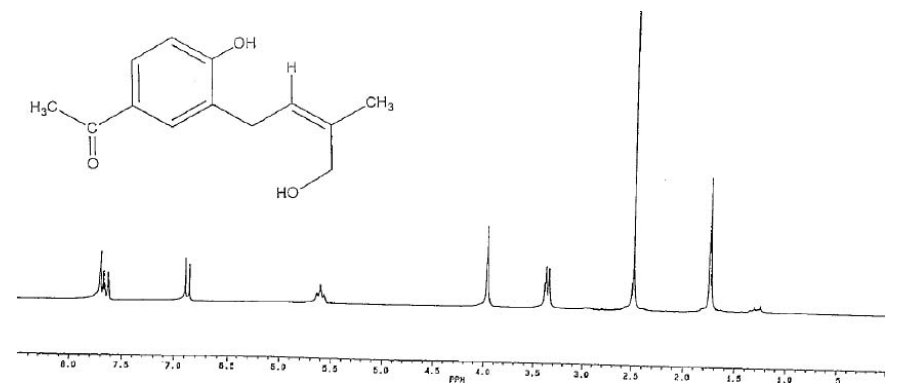

Figure 4: The ${ }^{1} \mathrm{H}-\mathrm{NMR}$ spectrum of 3-(2- Hydroxymethyl-2-buten4-yl)-4- hydroxyl-acetophenone isolated from A. monosperma.

\section{Mass Spectra}

The mass spectrum of each flavone displayed a molecular ion peak which matches its molecular formula. The fragmentation pattern was helpful in determining the substitution pattern because the resulting $\mathrm{C}$-ring fragments as well as those of $\mathrm{A}$ and $\mathrm{B}$ rings are typical for each flavone. ${ }^{34}$ For example, the structure of arcapillin was confirmed by the mass spectrum which revealed the presence of the $A$ and $B$ rings which is indicative of the two methoxyl groups in ring A (Figure 6). All isolated flavones showed similar fragmentation patterns. ${ }^{38-41}$ The mass spectrum 4-hydroxyacetophenone showed a molecular ion peak at m/e 136 which corresponds to its molecular weight and the mass spectrum of 3-(2-hydroxymethyl2-buten-4-yl)-4- hydroxyacetophenone showed a molecular ion peak at $\mathrm{m} / \mathrm{e} 202$ due to the loss of a water molecule (Figure 5).

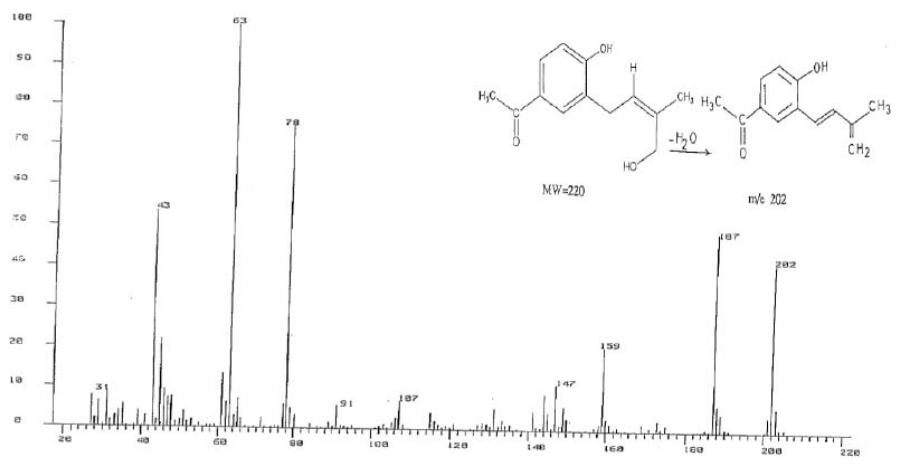

Figure 5: The mass spectra of 3-(2- Hydroxymethyl-2-buten-4-yl)-4-hydroxylacetophenone.
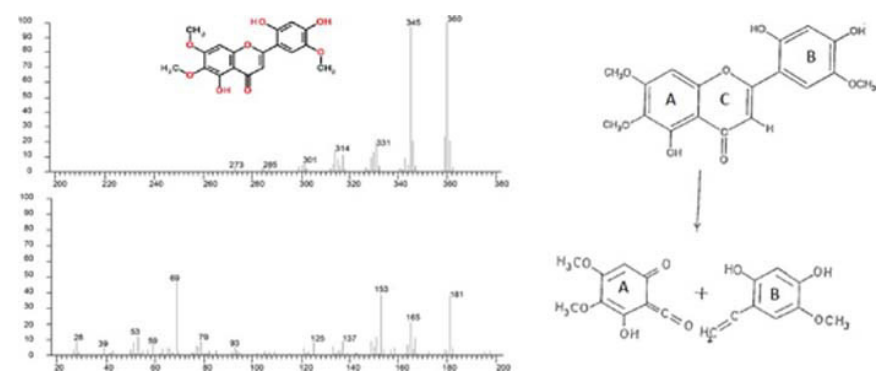

Figure 6: The mass spectrum and fragmentation pattern of Arcapillin.

\section{Ultraviolet Spectroscopy}

A summary for the UV spectral peaks under different conditions are listed in Table 2. The existence of a flavone nucleus is indicated by the UV spectrum of a flavone in methanol based on the appearance of two major absorption peaks; band I and band II. ${ }^{39}$ The range of absorption for each band and subsequent bathochromic shift and change in the magnitude of peak intensity upon addition of different reagents determined the functional groups on the flavone nucleus. ${ }^{34,39}$

The UV spectra for the two isolated acetophenone derivatives confirmed the presence of a phenolic group. The UV spectrum of 4-Hydroxyacetophenone in methanol showed a band at 277 which was shifted to 322 upon addition of sodium bicarbonate. This shift confirmed the presence of a phenolic hydroxyl group. The UV spectrum of 3-(2- hydroxymethyl2-buten-4-yl)-4- hydroxyacetophenone in methanol showed a band at 278 which was shifted to 354 upon addition of sodium methoxide indicating the presence of a phenolic group. 


\section{Proton Nuclear Magnetic Resonance ('H-NMR)}

${ }^{1} \mathrm{H}-\mathrm{NMR}$ spectra of isolated flavones are shown in Figure 2. Analysis of spectra for all isolated compounds was similar to literature data. ${ }^{40-42}$

The two isolated acetophenone derivatives were confirmed by analysis of their ${ }^{1} \mathrm{H}-\mathrm{NMR}$ spectra.

The 4-hydroxyacetophenone showed a single peak at $2.6 \mathrm{ppm}$ indicating the three protons of the acetyl group (Figure 3 ). The aromatic ring protons appeared as two doublets at $7.9 \mathrm{ppm}$ and $6.9 \mathrm{ppm}$, a typical pattern for the para-substituted phenyl rings. Analysis of its ${ }^{1} \mathrm{H}-\mathrm{NMR}$ spectrum (Figure 4) of 3-(2- Hydroxymethyl-2-buten-4-yl)-4- hydroxyacetophenone matches literature data. ${ }^{22}$

\section{CONCLUSION}

Artemisia monosperma is rich in different categories of secondary metabolites known for their diverse biological activities. Flavonoids subgroups are reputed for their potent antioxidant activity and for effectiveness against inflammation and aging. Thorough studies using Artemisia species are recommended to isolate new bioactive compounds in significant quantities that will allow further biological studies in order to identify drugs of natural origin against selective diseases including inflammatory associated diseases.

\section{ACKNOWLEDGEMENT}

The authors acknowledge Central State University for the provided technical support and University of Jordan for authentication of the plant.

\section{CONFLICT OF INTEREST}

The authors declared no conflict of interest.

\section{ABBREVIATIONS}

NMR: Nuclear Magnetic Resonance; UV: Ultraviolet; TLC: This Layer Chromatography; NaOCH: ${ }_{3}$ Sodium methoxide; $\mathbf{A l C I}_{3}$ : Aluminum Chloride; HCl: Hydrochloric Acid; ppm: parts per million.

\section{REFERENCES}

1. Abad MJ, Bedoya LM, Apaza L, Bermejo P. The Artemisia L. Genus: A Review of Bioactive Essential Oils. Molecules. 2012;17(3):2542-66.

2. Bora KS, Sharma A. The genus Artemisia: A comprehensive review. Pharmaceutical Biology. 2011;49(1):101-9

3. Migahid AM, Hammouda MA. Flora of Saudi Arabia 1974; $2^{\text {nd }}$ edn. p 445 Riyadh University publication, Riyadh. 1974

4. Dabe NE, Kefale AT. Antidiabetic effects of Artemisia species: A Systematic Review. ANC Sci Life. 2017;36(4):175-81.

5. Sharaf A, Fahmy IR, Ahmed ZF, Moneim FA. Pharmacological study of Artemisia monospermal. Egypt Pharml Bull. 1959;41:47-52.

6. Hijazi AM, Salhab AS. Effects of Artemisia monosperma ethanolic leaves extract on implantation, mid-term abortion and parturition of pregnant rats. Journal of Ethno pharmacology. 2010;128(2):446-51.

7. Shahat AA, Alsaid MS, Ibrahim A, Elsaid M. Polyphenolic content and antioxidant activity of some wild Saudi Arabian asteraceae plants. Asian Pacific Journal of Tropical Medicine. 2014;7(7):545-51.

8. Salhi N, Saghir SA, Terzi V, Brahmi I, Ghedairi N, Bissati S. Antifungal activity of aqueous extracts of some dominant Algerian medicinal plants. BioMed Research International. 2017;6. Article ID 7526291.

9. Zaki D, El-Aziz AM, El-Gengeihy S, Morsi N. Antimicrobial potentiation of some Egyptian desert plant. Herba Hungarica. 1984;23:73-84.

10. Abou-Taleb HK, Mohamed MI, Shawir MS, Abdelgaleil SA. Insecticidal properties of essential oils against Tribolium castaneum (Herbst) and their inhibitory effects on acetylcholin-esterase and adenosine triphosphatases. Nat Prod Res. 2016;30(6):710-4.

11. Abdel-Shafy S, El-Khateeb RM, Soliman MM, Abdel-Aziz MM. The efficacy of some wild medicinal plant extracts on the survival and development of third instar larvae of Chrysomyia albiceps (Wied) (Diptera: Calliphoridae). Trop Anim Health Prod. 2009;41(8):1741-53.
12. Maia MF, Moore SJ. Plant-based insect repellents: A review of their efficacy, development and testing. Malaria Journal. 2011;10(1)1-S11.

13. Saleh MA. An insecticidal diacetylene from Artemisia monosperma. Phytochemistry. 1984;23(11):2497-8.

14. Grech-Baran M, Pietrosiuk A. Artemisia species in vitro cultures for production of biologically active secondary metabolites. Bio Technologia. 2012;93(4):37180.

15. Ferreira JFS, Luthria DL, SasakiT, Heyerick A. Flavonoids from Artemisia annua L. As Antioxidants and Their Potential Synergism with Artemisinin against Malaria and Cancer. Molecules. 2010;15(5):3135-70.

16. Lone $\mathrm{SH}$, Bhat KA, Khuroo M. Arglabin: From isolation to antitumor evaluation". Chemico-Biological Interactions. 2015;240(5):180-98.

17. Abu-Niaaj L, Abu-Zarga M, Abdalla S. Isolation and Biological Effects of Eupatilin, a Flavone Isolated from Artemisia monosperma (Del.) on Rat Isolated Smooth Muscles. International Journal of Pharmacognosy. 1996;34(2):134-40.

18. Abu-Niaaj L, Abu-Zarga M, Sabri S, Abdalla S. Isolation and biological effects of 7-O-methyleriodictiol, a flavanone isolated from Artemisia monosperma, on rat isolated smooth muscles. Planta Medica. 1993;59(1):42-5

19. Ismail SI, Rizk AM, Hammouda FM, Hassan NM. Methylated flavonoids from Artemisia monosperma. Qatar Univ Sci Bull. 1989;9:79-84.

20. Saleh NA, El-Negoumy SI, Abou-Zaid MM. Flavanoids of Artemisia judaica, A. monosperma and A. herba-alba. Phytochemistry. 1987;26(11):3059-64.

21. Hammoda HM, Ela MA, El-Lakany AM, El-Hanbali O, Zaki CS, Ghazy NM. New constituents of Artemisia monosperma Del. Pharmazie. 2008;63(8):611-4.

22. Hammoda FM, Rizk AM, Ismail SI, Hassan NM. Isolation of an acetophenone derivative and coumarins from Artemisia monosperma Del. Fitoterapia. 1978;48:53-5

23. Pandey AK, Singh P. The Genus Artemisia: A 2012-2017 Literature review on chemical composition, antimicrobial, insecticidal and antioxidant activities of essential oils. Medicines. 2017;4(3):68. doi:10.3390.

24. Guetat A, Al-Ghamdi FA, Osman AK. The genus Artemisia L. in the Northern region of Saudi Arabia: Essential oil variability and antibacterial activities. Nat Prod Res Mar. 2017;31(5):598-603.

25. Zalabani SM, Tadros SH, El Sayed AM, Daboub AA, Sleem AA. Chemical profile and biological activities of essential oil of aerial parts of Artemisia monosperma Del. growing in Libya. Pharmacogn J. 2017:9(4):578-86.

26. Shahat AA, Alsaid MS, Alyahya MA, Higgins M, Dinkova-Kostova AT. NAD (P) $\mathrm{H}$ : quinone oxidoreductase 1 inducer activity of some Saudi Arabian medicinal plants. Planta Med. 2013:79(6):459-64.

27. Khan M, Mousa AA, Syamasundar KV, Alkhathlan HZ. Determination of chemical constituents of leaf and stem essential oils of Artemisia monosperma from central Saudi Arabia. Nat Prod Commun. 2012;7(8):1079-82.

28. El-Sheikh TM. Field evaluation of repellency effect of some plant extracts against mosquitoes in Egypt. J Egypt Soc Parasitol. 2009;39(1):59-72.

29. Abou-Zeid AM, Altalhi AD, Abd El-Fattah RI. Fungal control of pathogenic fungi isolated from wild plants in Taif Governorate, Saudia Arabia. Roum Arch Microbiol Immunol. 2007;66(3-4):90-6.

30. Stavri M, Ford CH, Bucar F, Streit B, Hall ML, Williamson RT, et al. Bioactive constituents of Artemisia monosperma. Phytochemistry. 2005;66(2):233-9.

31. Assar AA, El-Sobky MM. Biological and histopathological studies of some plant extracts on larvae of Culex pipiens (Diptera: Culicidae). J Egypt Soc Parasitol. 2003;33(1):189-200

32. Khafagy SM, El-Ghazouly MG, Metwally AM. Isolation and characterization of two methoxylated flavones from Artemisia monosperma. Pharmazie. 1979;34(11):748-9

33. Soliman MMM. Phytochemical and toxicological studies of Artemisia L. (Compositae) essential oil against some insect pests. Archives of Phytopathology and Plant Protection. 2007;40(2):128-38

34. Tsimogiannis D, Samiotaki M, Panayotou G, Oreopoulou V. Characterization of Flavonoid Subgroups and Hydroxy Substitution by HPLC-MS/MS. Molecules. 2007; 12(3):593-606.

35. Mohamed AE, El-Sayed MA, Hegazy ME, Helaly SE, Esmail AM, Mohamed NS. Chemical Constituents and Biological Activities of Artemisia herba-alba. Rec Nat Prod. 2010;4(1):1-25.

36. Namba T, Hattori M, Takehana $Y$, Tsunezuka M, Tomimori T, Kizu H, et al. A flavone from Artemisia capillaris. Phytochemistry. 1983;22(4):1057-8

37. Goudard M, Favre-Bonvin J, Strelisky J, Nogradi M, Chopin J. Differentiation des hydroxy-5 dimethoxy-6,7 ou 7,8 et des triméthoxy-5,6,7 ou 5,7,8 flavones par spectrometrie de masse. Phytochemistry. 1979;18(1):186-7.

38. Ching-Weng C, Yun-Chieh C, Yu-Chin L, Wen-Huang P. p-Hydroxyacetophenone suppresses nuclear factor- $\otimes B$-related inflammation in nociceptive and inflammatory animal models. Journal of Natural Medicines. 2017;71(2):422-32.

39. Mabry TJ, Markham KR, Thomas MB. The Ultraviolet Spectra of Flavones and Flavonols. In: The Systematic Identification of Flavonoids. 1970. Springer, Berlin, Heidelberg.

40. Mabry TJ, Markham KR, Thomas MB. The Determination and Interpretation of NMR Spectra of Flavonoids. In: The Systematic Identification of Flavonoids. 1970 Springer, Berlin, Heidelberg. 
41. Blunder M, Orthaber A, Bauer R, Bucar F, Kunert O. Efficient identification of flavones, flavanones and their glycosides in routine analysis via off-line combination of sensitive NMR and HPLC experiments. Food Chemistry. 2017;218: $600-9$.
42. Markham KR. Proton Nuclear Magnetic Resonance. Methods in Plant Biochemistry (Dey P. M. and Harborne J. B., Ed.). 1989, vol. 1, Academic Press, London, San Diego, New York, Boston, Sydney, Tokyo, Toronto, p. 213-223.

\section{SUMMARY}

- Artemisia mosopserma methanolic extract was fractionated to obtain nine flavone aglycones.

- This study reports four flavone aglycones for the first time from A. monosperma; 5-Hydroxy-3', 4',6,7-tetramethoxyflavone;3',5-dihydroxy-4',6,7-trimethoxyflavon e(eupatorin);5,6-dihydroxy-4',7-dimethoxyflavone (ladanein); and 2',4',5-trihydroxy-5',6,7-trimethoxyflavone (arcapillin).

- This study reports five flavone glycones previously identified from A. monosperma and these are:4',5-Dihydroxy-3',6,7-trimethoxyflavone(cirsilineol):5,7-dihydroxy3',4',6-trimethoxyflavone (eupatilin);4',5,7-trihydroxy-3',6-dimethoxyflavone(jaceosidin);4',5-dihydroxy-6,7-dimethoxy-flavone (circimaritin) and 4',5,7-trihydroxy6-methoxyflavone (hispidulin).

- Two acetophenone derivatives were isolated;4-hydroxyacetophenone from the fraction yielded jaceosidin and 3-(2-hydroxymethyl-2-buten-4-yl)-4-hydroxyacetophenone from both fractions yielded circimaritin and arcapillin.

Cite this article: Abu-Niaaj L, Katampe I. Isolation and Characterization of Flavones from Artemisia monosperma, Pharmacogn J. 2018;10(5):1018-23. 